\title{
Neuronal Nitric Oxide Synthase Plays a Key Role in CNS Demyelination
}

\author{
David Liñares, ${ }^{1}$ Maaike Taconis, ${ }^{1}$ Paula Maña, ${ }^{2}$ Manuel Correcha, ${ }^{1}$ Sue Fordham, ${ }^{1}$ Maria Staykova, ${ }^{1}$ and \\ David 0. Willenborg ${ }^{1}$ \\ ${ }^{1}$ Neurosciences Research Unit, Australian National University Medical School, Canberra Hospital, and ${ }^{2}$ The John Curtin School of Medical Research, \\ Australia National University, Canberra, Australian Capital Territory 2601, Australia
}

\begin{abstract}
Nitric oxide (NO) is a small, short-lived molecule released from a variety of cells that is implicated in a multitude of biological processes. In pathological conditions, overproduction of NO may lead to the generation of highly reactive species, such as peroxynitrite and stable nitrosothiols, that may cause irreversible cell damage. Accordingly, several studies have suggested that NO may be involved in the pathogenesis of various neuroinflammatory/degenerative diseases. Increased concentrations of NO in the CNS in such cases are usually attributed to an increase in the inducible isoform of NO synthase (iNOS) usually produced by inflammatory cells. However, recent reports have suggested that the constitutive isoforms of NOS, neuronal (nNOS) and endothelial (eNOS), can also play a role. Here we examined the role that the constitutive isoforms of NOS might play in the cuprizone-induced model of demyelination/remyelination. Our results demonstrate that demyelination was greatly prevented in mice lacking nNOS. Protection was associated with a dramatic increase in mature oligodendrocyte survival and a decrease in apoptosis. Moreover, $n \mathrm{NOS}^{-/-}$mice did not respond to cuprizone with the extensive recruitment of microglia/macrophages and astrocytes, which is a typical feature in wild-type mice. Although demyelinating less, $n \mathrm{NOS}^{-/-}$mice exhibited a delay in remyelination. In $\mathrm{NOS}^{-/-}$mice, demyelination progressed to the same extent as in wild type, but they showed a slight delay in spontaneous remyelination. In conclusion, this study highlights the importance of considering the source of NO when assessing its role in neuroinflammation/degeneration and emphasizes the differing pathological effects driven by the different NOS isoforms.
\end{abstract}

Key words: cuprizone; nNOS; eNOS; demyelination; remyelination; oligodendrocytes

\section{Introduction}

Multiple sclerosis (MS) is a complex inflammatory demyelinating disease; its etiology is believed multifactorial and essentially unknown. Perhaps, one of the most frustrating drawbacks encountered in the treatment of MS patients is the inadequacy of the healing response known as remyelination. Details of the process of remyelination have been somewhat difficult to ascertain because, in most experimental models of demyelination/remyelination, the severity, lesion localization, or time course of the pathophysiology are quite variable. Recently, the model originally described by Suzuki and Kikkawa (1969) has been revived in which feeding of mice with the copper chelator cuprizone in-

\footnotetext{
Received Sept. 21, 2005; revised 0ct. 26, 2006; accepted 0ct. 26, 2006.

This work was supported by grants from MS Australia and The National Health and Medical Research Council of Australia. D.O.W. is a Senior Research Fellow of National Health and Medical Research Council of Australia. D.L. was supported by a fellowship from Fundacion Caixa-Galicia and Multiple Sclerosis Society of Australia. M.T. was supported by Stichting Multiple Sclerose, Hersenstichting Nederland, and Serono International. The technical expertise of Elaine Bean in preparation and staining sections for light microscopy is gratefully acknowledged. We thank Roger McCart, Anne Prins, Cathy Gillespie, and Mark Koina for the preparation and photography of sections for light and electron microscopy. We acknowledge Nathan $0^{\prime}$ Callaghan for his kind support and help with real-time PCR. We also thank Antonio Quesada Hervas for his assistance in graphic designing.

Correspondence should be addressed to David Liñares, Neuroscience Research Unit, Australian National University Medical School, The Canberra Hospital, P.0. Box 11, Woden, Canberra, Australian Capital Territory 2606, Australia. E-mail: david.linares@anu.edu.au or rosellon@usc.es.

DOI:10.1523/JNEUROSCI.0294-06.2006

Copyright $\odot 2006$ Society for Neuroscience ～0270-6474/06/2612672-10\$15.00/0
}

duces demyelination restricted to the corpus callosum and superior cerebellar peduncles. When the cuprizone challenge is terminated, an almost complete remyelination takes place in a matter of weeks (Matsushima and Morell, 2001). The molecular basis of this process of demyelination/remyelination is not understood, but studies have pointed that various cytokines and reactive molecules take part in the process (Popko et al., 1997; Mason et al., 2000, 2003; Arnett et al., 2001; Plant et al., 2005). Of particular interest here is the report that nitric oxide produced by inducible nitric oxide synthase (iNOS) is moderately protective in this model of demyelination (Arnett et al., 2002).

Nitric oxide (NO) is a highly reactive molecule with diverse physiological functions, found in many types of cells (Nathan and Xie, 1994). In addition to the inducible form mentioned above, there are two more constitutive forms of the enzyme: endothelial (eNOS) and neuronal (nNOS). iNOS is most often associated with inflammatory conditions in which it is produced in large amounts by monocyte/macrophage lineage cell types. In the CNS, iNOS is not significantly expressed by resident cells unless cellular activation occurs, after which iNOS is produced by several types of cells, such as macrophages, microglia, astrocytes (Simmons and Murphy, 1992; Hewett et al., 1993), oligodendrocytes (Merrill et al., 1997), and even cerebral endothelial cells (Borgerding and Murphy, 1995). nNOS and eNOS are constitutively expressed in the CNS in which they play an essential role in 
several processes, including intracellular signaling, neurotransmission, and vasoregulation (Bredt and Snyder, 1992; Murphy et al., 1993). Besides being constitutively driven by calmodulin or increases in intracellular calcium, under some circumstances, nNOS and eNOS are also inducible (Murphy et al., 1993; Ma et al., 1994). In fact, eNOS and nNOS genes incorporate putative promoter region containing consensus sequences for activator protein 2, acute-phase reactants, nuclear factor 1, shear stress (for eNOS), and nuclear factor $\kappa \mathrm{B}$ (for nNOS) (Moro et al., 2004). Because little is known about the role of NO derived from nNOS and eNOS in demyelinating diseases, in the present study, we examined the role that nNOS and eNOS play in the demyelination and remyelination process by using the demyelination model induced by cuprizone. Our results show that the lack of the constitutive isoforms for NOS influences the demyelination and remyelination processes. Moreover, the data derived from the current study suggest a key role for the neuronal NOS isoform in promoting demyelination in response to the chemical insult.

\section{Materials and Methods}

Animals. Studies were conducted on 10- to 12-week-old male mice on C57BL/6 background. Breeding pairs of homozygous mutant mice lacking the gene for neuronal NOS $\left(n \mathrm{NOS}^{-/-}\right)$or endothelial NOS $\left(\mathrm{eNOS}^{-/-}\right)$were obtained from Paul Huang at Massachusetts General Hospital (Boston, MA) (Huang et al., 1994, 1996). Age- and sex-matched wild-type littermate C57BL/6 controls were used in the studies. Mice were maintained in pathogen-free conditions and used between the ages of 8 and 14 weeks. All animal experimentation was approved by the Animal Experimentation Ethics Committee of the Australian National University.

Induction of demyelination and remyelination. To induce demyelination, $n N O S^{-1-}$ and $e \mathrm{NOS}^{-1-}$ mice and their respective littermates controls were fed $0.25 \%$ cuprizone mixed with ground chow. After 4 weeks of feeding, normal food was restored for an additional 4 weeks. Food was provided ad libitum, and levels were checked daily.

Histology and immunohistochemistry. For histological examination, mice were killed and perfused intracardially with $15 \mathrm{ml}$ of $4 \%$ paraformaldehyde in PBS. Brains were removed and fixed in $4 \%$ paraformaldehyde for 1 week. Brains were then placed in a David Kopf Instruments (Tujunga, CA) brain blocker and trimmed at a level $2 \mathrm{~mm}$ anterior to bregma. Serial coronal sections were examined between levels 1 and -1 $\mathrm{mm}$ bregma according to the mouse brain atlas of Franklin and Paxinos (1997).

Demyelination was evaluated in $5 \mu \mathrm{m}$ paraffin sections of the corpus callosum using Luxol fast blue (LFB) with periodic acid-Schiff reaction. Myelin was also immunostained with monoclonal antibody (mAb) 8-18C5, which recognizes myelin oligodendrocyte glycoprotein (MOG). Briefly, mouse anti-MOG mAb (clone 8-18C5) (Linnington et al., 1984) was purified from hybridomas on a Protein G-Sepharose 4B Fast Flow column (Thermo Electron Corporation, Waltham, MA) according to the instructions of the manufacturer. Antigen retrieval was performed by heating the sections in citrate buffer, $\mathrm{pH} 6.0$, at $90^{\circ} \mathrm{C}$ for $20 \mathrm{~min}$ (Shi et al., 2002). Sections were incubated with $0.3 \%$ of $\mathrm{H}_{2} \mathrm{O}_{2}$ in methanol for $3 \mathrm{~min}$ at room temperature (RT) for quenching endogenous peroxidase activity, blocked with 5\% BSA/PBS for $1 \mathrm{~h}$ at RT, and incubated with 8-18C5 antibody $(\mathrm{Ab})$ at $20 \mu \mathrm{g} / \mathrm{ml}$. Sections were then incubated with 1:500 of anti-mouse IgG1-biotin (Chemicon, Temecula, CA). After rinsing, they were incubated for $1 \mathrm{~h}$ with streptavidin-horseradish peroxidase (InnoGenex, San Ramon, CA) and with 3-amino-9-ethylcarbazole (AEC) substrate (InnoGenex). Demyelination score was evaluated by two independent readers using a five-point scale, ranging from 0 (no demyelination) to 5 (total demyelination of corpus callosum). At least four sections at three different levels were examined for each mouse. Results were expressed as average of at least four mice per group.

Paraffin-embedded sections were stained for the $\pi$ isoform of glutathione $S$-transferase (GST- $\pi$ ) (a marker of mature oligodendrocytes), Ricinus communis aglutin-1 (RCA-1) (a marker for microglia/macro- phages), and glial fibrillary acidic protein (GFAP) a marker for astrocytes). Briefly, for GST- $\pi$ and GFAP staining, antigen retrieval was performed by boiling sections in citrate buffer, $\mathrm{pH}$ 6.0, for $30 \mathrm{~min}$. Sections were incubated with $0.3 \%$ of $\mathrm{H}_{2} \mathrm{O}_{2}$ in methanol for 3 min at RT for quenching endogenous peroxidase activity, blocked with 5\% BSA/PBS for $1 \mathrm{~h}$ at RT, and incubated with 1:500 and 1:1000 of rabbit anti-GFAP $\mathrm{Ab}$ and rabbit anti-GST- $\pi \mathrm{Ab}$ (Chemicon), respectively. After rinsing, the sections were incubated with goat anti-rabbit IgG-HRP (Chemicon) and with AEC substrate pack (InnoGenex). For macrophages and microglia staining, antigen retrieval was performed by incubating with proteinase-K (Fermentas, Hanover, MA) for $2 \mathrm{~min}$ at $43^{\circ} \mathrm{C}$. Sections were then incubated with biotinylated RCA-1 (Vector Laboratories, Burlingame, $\mathrm{CA}$ ) for $1 \mathrm{~h}$ at room temperature. After rinsing, they were incubated with streptavidin-horseradish peroxidase and then with AEC substrate.

To identify apoptosis in the corpus callosum, the ApopTag Peroxidase In Situ Oligo Ligation Apoptosis Detection kit (Chemicon) was used on paraffin sections. Briefly, $5 \mu \mathrm{m}$ paraffin sections were incubated with $3 \%$ of $\mathrm{H}_{2} \mathrm{O}_{2}$ in $\mathrm{PBS}$ to quench endogenous peroxidase activity. Antigen retrieval was performed by boiling sections in citrate buffer, $\mathrm{pH} 6.0$, for 30 $\mathrm{min}$. Sections were incubated with Apoptag equilibration buffer (Chemicon) for $1 \mathrm{~min}$ at RT, followed by a mixture of T4 DNA ligase and a blunt-ended biotinylated oligo (Chemicon) for $18 \mathrm{~h}$ at $4^{\circ} \mathrm{C}$. Sections were further exposed to streptavidin-peroxidase for $1 \mathrm{~h}$ at $\mathrm{RT}$, and the positive reaction was visualized with diaminobenzidine as substrate (Chemicon). For cell quantification, three fields of the corpus callosum were examined from each animal by two different observers. Results are expressed as average \pm SD of at least three mice per group in each time point.

For staining of mature oligodendrocytes and oligodendrocyte precursors (OPCs), mice were killed and perfused intracardially with cold PBS for $15 \mathrm{~min}$. Brains were removed and trimmed and were immediately frozen in cold isopentane on dry ice before being stored at $-70^{\circ} \mathrm{C}$. Sections at $10 \mu \mathrm{m}$ were fixed with cold acetone for $30 \mathrm{~min}$, and endogenous peroxidase activity was quenched with $0.3 \%$ of $\mathrm{H}_{2} \mathrm{O}_{2}$ in methanol. Sections were incubated overnight at $4^{\circ} \mathrm{C}$ with adenomatous polyposis coli antibody (CC-1) (Abcam, Cambridge, MA) at dilution 1:20 for mature oligodendrocytes and rabbit anti-NG2 (Chemicon) at dilution 1:400 for OPCs. As secondary antibody, goat anti-mouse IgG-HRP or goat antirabbit IgG-HRP (Chemicon) were used, and the positive reaction was visualized with AEC substrate (InnoGenex). For cell quantification, three fields of corpus callosum immunostained for GST- $\pi$ or NG2 were examined from each animal by two different observers. Cell counts are expressed as the mean number in the three sections per animal at each time point. Results are expressed as average of at least four mice per group for GST- $\pi$ and three mice per group for NG2. Analysis was performed using a Nikon (Tokyo, Japan) digital camera D100 and Nikon capture software.

Electron microscopy. For electron microscopy, mice were anesthetized and perfused with $2.5 \%$ glutaraldehyde in $0.1 \mathrm{~m}$ sodium cacodylate buffer. Brains were removed and fixed for an additional $12 \mathrm{~h}$ in $2.5 \%$ glutaraldehyde. Brains were then placed in a David Kopf Instruments brain blocker, trimmed at a level $2 \mathrm{~mm}$ anterior to bregma, and sliced into $1 \mathrm{~mm}$ sections. Sections were reoriented in a way that allowed performing cross sections of the corpus callosum. Sections were further trimmed and postfixed for $90 \mathrm{~min}$ in $1 \%$ osmium tetroxide. They were then washed in distilled water, dehydrated in a graded acetone series, and embedded in Spurr's resin. Ultrathin sections were cut with an ultramicrotome and viewed and photographed with Toshiba (New York, NY) transmission electron microscope. For each mouse, myelinated and unmyelinated axons were counted from three different electron micrograph images.

RNA analysis. Mice were perfused with cold PBS, and brains were removed and trimmed $1 \mathrm{~mm}$ anterior to bregma using the David Kopf Instruments brain blocker. Five milligrams of corpus callosum were taken from each brain with a glass Pasteur pipette under dissecting microscope. Total RNA was prepared using Trizol technology (Invitrogen, Melbourne, Victoria, Australia). Purity of the RNA was determined by A260/A280. RNA $(5 \mu \mathrm{g})$ for each sample was reverse transcribed into cDNA using Omniscript RT kit (Qiagen, Doncaster, Victoria, Australia). 
For quantitative real-time PCR, first-strand cDNA was synthesized as above. SYBR-Green-based real-time PCR was used to measure relative gene expression of tumor necrosis factor- $\alpha$ (TNF $\alpha)$, IGF-1, interleukin- $1 \beta$ (IL-1 $\beta$ ), iNOS, nNOS, eNOS, and MOG in each sample. Each master mix $(20 \mathrm{ml})$ contained a single gene-specific primer set (sense and antisense, $2.5 \mathrm{~mm}$ ), $20 \mathrm{ng}$ of $\mathrm{cDNA}$, and $2 \times$ SYBR-Green PCR master mix (Applied Biosystems, Foster City, CA). Each experimental sample was assayed using three replicates for each primer, including the $\beta$-actin-specific primer that was used as an internal standard. Negative controls lacking the cDNA template were run with every assay to assess specificity. Primer Express software (Applied Biosystems) was used for primer design. Gene-specific primer sets were designed to span intronexon junctions to discriminate between $c D N A$ and genomic DNA. The primer sets used in these studies were as follows: $\beta$-actin sense, $5^{\prime}$-CGT GAA AAG ATG ACC CAG AT CA- $3^{\prime}$; antisense, $5^{\prime}$-CAC AGC CTG GAT GGC TAC GT-3; IL- $1 \beta$ sense, $5^{\prime}$-CAA CCA ACA AGT GAT ATT CTC CAT G-3'; antisense, $5^{\prime}$-GAT CCA CAC TCT CCA GCT GCA-3'; TNF $\alpha$ sense, 5'-GGG CCA CCA CGC TCT TC-3'; antisense, 5'-GGT CTG GGC CAT AGA ACT GAT G-3; IGF-1 sense, $5^{\prime}$-CCA CAC TGA CAT GCC CAA GA-3'; antisense, 5' -CTC CTT TGC AGC TTC GTT TTC T-3'; iNOS sense, $5^{\prime}$-AGA GAG ATC CGA TTT AGA GTC TTG GT-3'; antisense, $5^{\prime}$-TGA CCC GTG AAG CCA TGA C-3; nNOS sense, $5^{\prime}$-TCC TAA ATC CAG CCG ATC GA-3'; antisense, 5' - TCA TGG TTG CCA GGG AAG AC-3; eNOS sense, 5' -GGA AAT GTC AGG CCC GTA CA3'; antisense, 5'-GGT CTG AGC AGG AGA CAC TGT TG-3; MOG sense, 5'-GCA GCA CAG ACT GAG AGG AAA A-3'; and antisense, 5'-GCA CCC TCA GGA AGT GAG GAT-3. PCR amplification was performed in 7300 Sequence Detection PCR system (Applied Biosystems). The cycling conditions were as follows: one cycle at $95^{\circ} \mathrm{C}$ for $10 \mathrm{~min}$, followed by 40 cycles of PCR amplification, each consisting of $95^{\circ} \mathrm{C}$ for $15 \mathrm{~s}$ and $60^{\circ} \mathrm{C}$ for $45 \mathrm{~s}$. Sequence Detection Software (SDS version 1.2.2; Applied Biosystems) was used for analysis of the results. A threshold cycle (Ct) was determined for each sample. PCR assays showing nonspecific products at the end point were excluded from additional data analysis. Relative quantification using comparative $\mathrm{Ct}$ method was used for analyzing results (Livak and Schmittgen, 2001). The results were expressed as relative fold change over the values for untreated mice.

Statistical analysis. Data were expressed as a mean \pm SD. Statistical analysis was performed using the GraphPrism program package, version 4 (GraphPad Software, San Diego, CA). Data was evaluated by performing two-way ANOVA and Bonferroni's tests, as appropriate. A value of $p<0.05$ was considered to be statistically significant.

\section{Results \\ $n \mathrm{NOS}^{-/-}$mice are virtually resistant to CNS demyelination induced by cuprizone feeding}

In normal conditions, nNOS is constitutively expressed by neurons and astrocytes in the CNS. However, several reports have indicated that the expression of nNOS can also be induced; particularly, an upregulation in its expression has been documented in certain pathological conditions (Wu et al., 1998, 2001). Accordingly, we first evaluated whether the expression of nNOS was altered in response to cuprizone treatment. As shown in Figure $1 \mathrm{~A}$, the expression of nNOS was markedly upregulated in the corpus callosum at weeks 3 and 4 of feeding. However, once cuprizone was removed from the diet, nNOS $\mathrm{m} R N A$ expression returned to basal levels. Conversely, the expression of eNOS did not appear to vary in response to cuprizone treatment (Fig. $1 B$ ). We next evaluated whether the lack of nNOS influences the demyelination and remyelination process associated with cuprizone administration. Figure $2 \mathrm{~A}$ shows that, before cuprizone exposure, the corpus callosum of $n \mathrm{NOS}^{-/-}$mice was myelinated to the same extent as the wild-type mice. After 3 weeks of exposure to the neurotoxicant, loss of myelin staining became evident in the edges of the corpus callosum of wild-type mice. At this time point, $n \mathrm{NOS}^{-1-}$ mice did not show any sign of demyelination. The differences in the extent of demyelination between groups

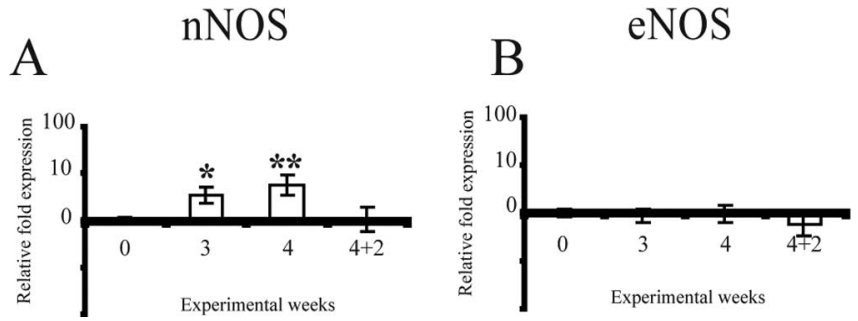

Figure 1. Relative expression of nNOS $(\boldsymbol{A})$ and eNOS $(\boldsymbol{B})$ during demyelination and remyelination induced by cuprizone in wild-type mice. mRNA was isolated from the corpus callosum of wild-type mice, and quantitative real-time PCR using gene-specific primers for nNOS $(A)$ and eNOS $(\boldsymbol{B})$ was performed. $\beta$-Actin gene was used for normalization. The results are expressed as relative fold change over untreated mice. ${ }^{*} p<0.05 ;{ }^{* *} p<0.01$.

became more dramatic after 4 weeks of cuprizone feeding. Whereas the corpus callosum of wild-type mice progressed to complete demyelination, $n \mathrm{NOS}^{-1-}$ mice demonstrated minor loss of myelin staining, restricted to the lateral edges of the corpus callosum (Fig. 2A,B).

After 4 weeks, cuprizone was removed from the diet to evaluate remyelination. As shown in the Figure 2A, 2 weeks after normal food was reestablished, consistent remyelination was apparent in the medial region of the corpus callosum of wild-type mice. Conversely, the lesioned edges of nNOS mice remained demyelinated at this time point, indicating that either $n \mathrm{NOS}^{-/-}$mice carry a partial impairment in their ability to remyelinate in response to cuprizone or that the required mechanisms needed for remyelination have not been generated in these mice because of the lack of a consistent demyelination. Four weeks after cuprizone removal, myelin staining was evident in the entire area of the corpus callosum of both experimental groups, which suggests that the impairment in remyelination efficiency showed by $n \mathrm{NOS}^{-/-}$mice was a transient phenomenon. Altogether, our results indicate that the expression of nNOS plays an essential role in the demyelinating syndrome associated with cuprizone feeding (Fig. 2B). We next investigated whether the lack of eNOS alters the demyelination and remyelination process instigated by the neurotoxicant. By week 4, both wild-type and $e \mathrm{NOS}^{-/-}$mice progressed to almost complete demyelination (Fig. $2 D, E$ ). When remyelination was assayed, a slight reduction in the extent of remyelination was observed in $e \mathrm{NOS}^{-1-}$ mice compared with wild-type control mice (Fig. 2D,E). However, at the termination of the experiment, extensive remyelination was evident in both experimental groups.

MOG is a CNS-specific protein exclusively localized in the myelin. Its expression appears late in development compared with other myelin proteins (Quarles, 1997). MOG expression is restricted to mature oligodendrocytes, which make it an excellent marker for myelin deposition (Solly et al., 1996). Immunostaining of the corpus callosum using the monoclonal Ab 8-18C5 revealed a marked reduction in the extent of MOG immunostaining in wild-type mice that have been fed cuprizone for 4 weeks. In contrast, little differences were observed after 4 weeks of cuprizone exposure in $n \mathrm{NOS}^{-/-}$mice compared with untreated mice (Fig. 2C). Figure $2 \mathrm{~F}$ shows no consistent differences in MOG staining between $e \mathrm{NOS}^{-/-}$and wild-type mice during acute demyelination. However, when normal food was restored, the recovery in the extent of MOG immunostaining appears to be reduced in $e \mathrm{NOS}^{-/-}$compared with wild-type control mice (Fig. $2 F$ ).

The differences observed in demyelination between $n \mathrm{NOS}^{-/-}$ and wild-type mice were further confirmed using electron 
A
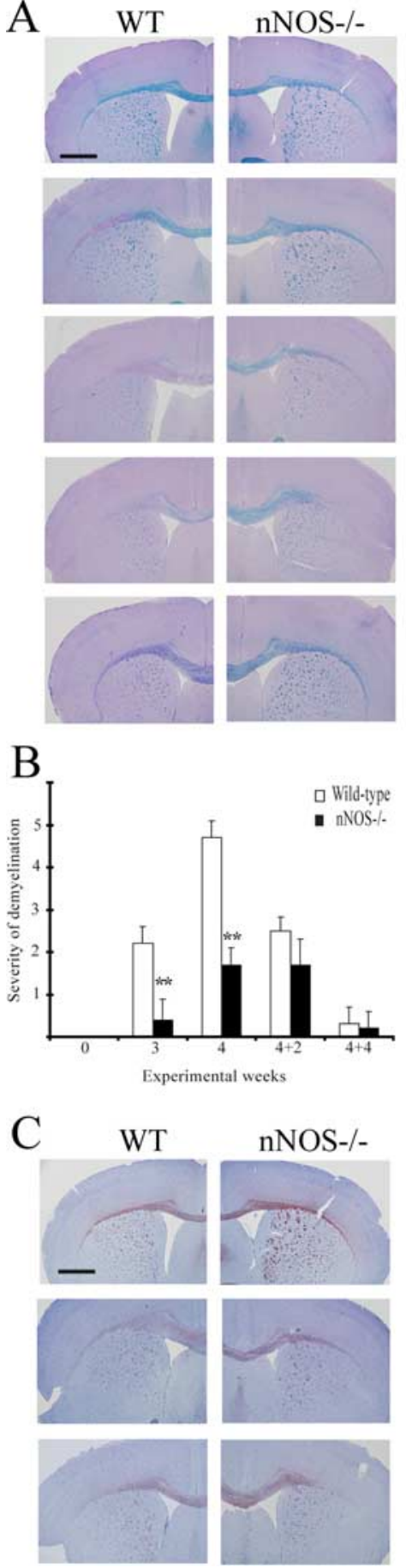

$\mathrm{D}$

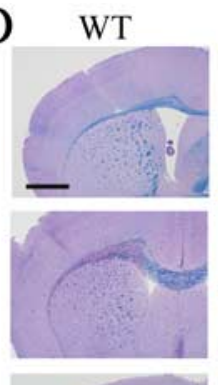

eNOS-/-

Control

3 weeks

$4+4$ weeks

4 weeks

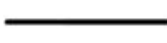

$4+2$ weeks
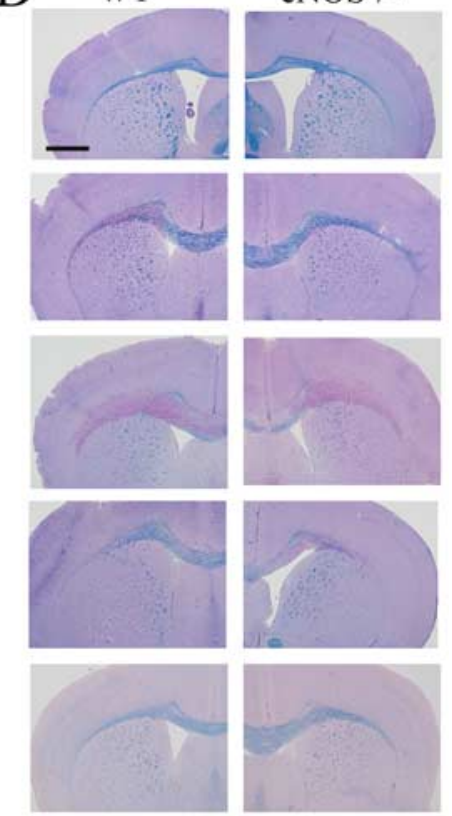

$\mathrm{E}$

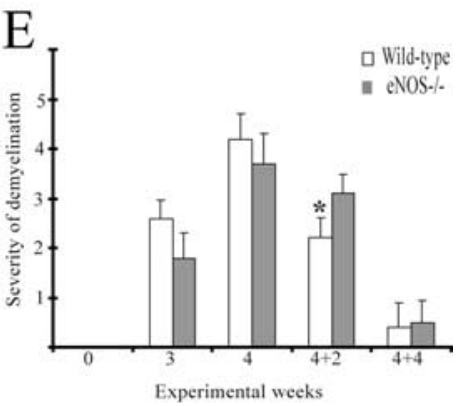

F

Control

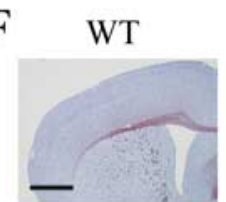

eNOS-/-

4 weeks
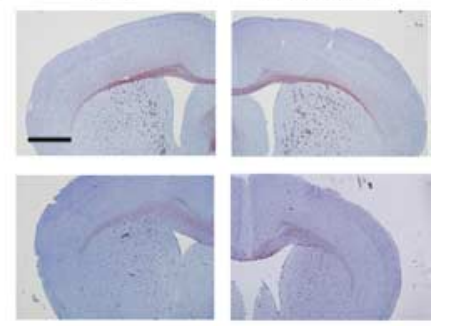

$4+2$ weeks
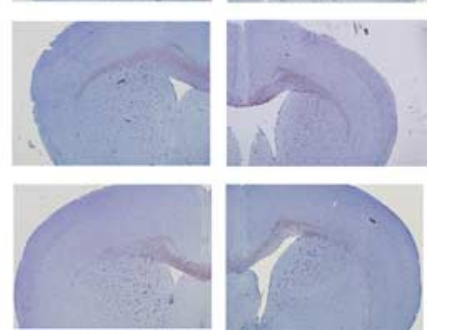

Figure 2. $n N O S^{-1-}$ mice are resistant to CNS demyelination induced by feeding with the copper chelator cuprizone. $n \mathrm{NOS}^{-/-}(\boldsymbol{A})$ and eNOS ${ }^{-1-}(\boldsymbol{D})$ mice together with their respective wild-type controls were fed with cuprizone for 4 weeks, and coronal brain sections at the level of the corpus callosum were stained with LFB with periodic acid-Schiff reaction at three time points. After cuprizone feeding, mice were fed for another 4 weeks with normal food to evaluate spontaneous remyelination. Semiquantitative data of the extent of demyelination of the corpus callosum, including middle part and lateral sides, for $n N O S^{-1-}$ mice $(\boldsymbol{B})$ and $\mathrm{NOS}^{-1-}$ mice $(\boldsymbol{E})$ were assessed by two independent observers in a blind manner as described in Materials and Methods. Representative coronal sections at the level of the corpus callosum of $n N \mathrm{~S}^{-1-}(\boldsymbol{C})$ and $\mathrm{eNOS}^{-1-}(\boldsymbol{F})$ mice were also immunostained with the monoclonal antibody 8-18C5, which recognizes MOG. Scale bar, $500 \mu \mathrm{m}$. ${ }^{*} p<0.05 ;{ }^{* *} p<0.01$.

microscopy. Representative electron micrograph of the corpus callosum from $n \mathrm{NOS}^{-/-}, \mathrm{eNOS}^{-/-}$, and wild-type mice are shown in Figures 3 and 4. Demyelination was also evaluated by estimating the percentage of unmyelinated axons during different time points of the treatment. As shown in Figure 3, the num- ber of myelinated axons dramatically decreases in wild-type mice after 4 weeks of cuprizone exposure. Remyelination was corroborated by the large proportion of axons that appear to be sheathed by new layers of myelin after 4 weeks of cuprizone removal. With electron microscopy, it was especially evident that the majority of axons of $n \mathrm{NOS}^{-/-}$mice preserve their myelin sheath throughout the whole experimental period with just a marginal decrease in the number of myelinated fibers observed in response to the treatment. During remyelination, only a modest recovery in the number of myelinated axons was observed in $n \mathrm{NOS}^{-/-}$mice. Figure 4 shows no consistent differences in the number of unmyelinated axons between $e \mathrm{NOS}^{-/-}$and wild-type mice in response to the treatment.

\section{Mice lacking nNOS show a dramatic decrease in the inflammatory cellular infiltrate in response to cuprizone treatment}

It has been shown previously that cuprizone exposure results in an extensive recruitment of activated microglia/macrophages in the demyelinating areas (McMahon et al., 2002). Concomitantly, several authors have also reported an extensive astrocytosis in response to cuprizone intoxication (Matsushima and Morell, 2001). Accordingly, we next evaluated the extent of the inflammatory cell infiltrate in mice lacking $\mathrm{nNOS}$ or eNOS expression. As shown in Figure $5 \mathrm{~A}, n \mathrm{NOS}^{-1-}$ mice showed little accumulation of RCA-1-positive cells after 4 weeks of treatment. In sharp contrast, RCA-1-positive cells were present in the corpus callosum of wild-type mice as early as week 3 and continued to increase by week 4 (Fig. 5A). The number of RCA-1-positive cells was consistently decreased when cuprizone was removed from the diet, with residual RCA-1 immunostaining after 4 weeks of normal feed (data not shown). No significant differences in the number of RCA-1positive cells were observed between $e \mathrm{NOS}^{-/-}$and wild-type mice (Fig. 5C). GFAP antibody was used to evaluate astrocytosis in response to the neurotoxicant exposure. In accordance with the reduced demyelinating syndrome showed by $n N O S^{-/-}$ mice, GFAP-positive cells were almost absent during the whole experimental period in these mice. In contrast, at weeks 3 and 4 , activated astrocytes were observed inside and outside the corpus callosum in wild-type mice (Fig. 5B). Residual astrocytosis was still apparent in wild-type mice 4 weeks after cuprizone removal (data not shown). Figure $5 D$ shows that no significant differences were observed in the number of GFAP-positive cells between wild-type and $e \mathrm{NOS}^{-/-}$mice. 


\section{Loss of mature oligodendrocytes is significantly inhibited in mice lacking nNOS}

The demyelination instigated by cuprizone feeding has been associated with an extensive oligodendrocyte death in the corpus callosum (Matsushima and Morell, 2001). Therefore, we asked whether the observed differences in demyelination between $n \mathrm{NOS}^{-/-}, \mathrm{eNOS}^{-/-}$, and wild-type mice could be related to a distinctive survival rate of mature oligodendrocytes during demyelination. Before treatment with cuprizone, $n \mathrm{NOS}^{-/-}, \mathrm{NOS}^{-/-}$, and wildtype mice exhibited equal numbers of mature oligodendrocytes in the corpus callosum (Fig. 6A-F). During demyelination, the number of oligodendrocytes was readily reduced in wild-type mice (Fig. $6 A-F)$. Conversely, only a slight decrease in the number of either GST- $\pi$ - or CC-1positive cells was appreciated in $\mathrm{nNOS}^{-/-}$ mice, thus explaining the dramatic differences observed in myelin staining between $n \mathrm{NOS}^{-1-}$ and wild-type mice during demyelination (Fig. 6A,C,E). When cuprizone was eliminated from the diet, a rapid recovery in the number of mature oligodendrocytes was observed in wild-type mice, and only a small increase in the number of GST- $\pi$-positive cells was noted in $n N^{-1-}$ mice (Fig. $6 A, E$ ). These results suggest that mature oligodendrocytes appear to be protected in mice lacking nNOS during acute demyelination.

Figure $6, B, D$, and $F$, shows no differences in the number of mature oligodendrocytes between $\mathrm{eNOS}^{-/-}$and wild-type mice during demyelination. NOS $^{-/-}$ mice show a delay in the generation of new mature oligodendrocytes when normal food was restored, although this was not significant. The higher numbers of GST$\pi$-positive cells observed in wild-type mice 2 weeks after cuprizone removal may be well in accordance with their accelerated remyelination observed using LFB and MOG immunostaining compared with $\mathrm{eNOS}^{-/-}$mice.

It has been documented previously that apoptosis is the main mechanism leading to oligodendrocyte death in the corpus callosum after cuprizone exposure (Arnett et al., 2002). Accordingly, sections were stained for apoptosis using Apoptag Peroxidase in situ Apoptosis Detection kit as described in Materials and Methods. Figure $7 A$ shows that a high number of cells from wild-type mice undergo apoptosis at 3 and 4 weeks of feeding. At week 6, when normal food was reestablished, the number of apoptotic cells was dramatically reduced in those mice (Fig. 7A). In contrast, only few apoptotic cells were detected in $n N O S^{-1-}$ mice in response to cuprizone, suggesting that lack of nNOS appears to protect mature oligodendrocytes from undergoing apoptosis during acute demyelination. We did not observe differences in the number of cells undergoing apoptosis between $\mathrm{eNOS}^{-/-}$and wild-type mice during treatment (Fig. 7B). experiments.

\section{WT}
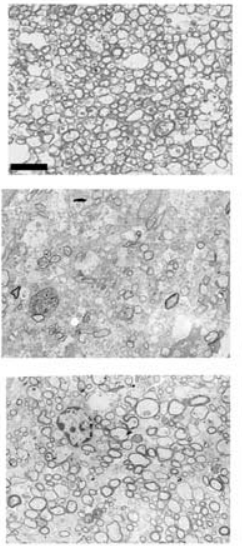

nNOS-/-
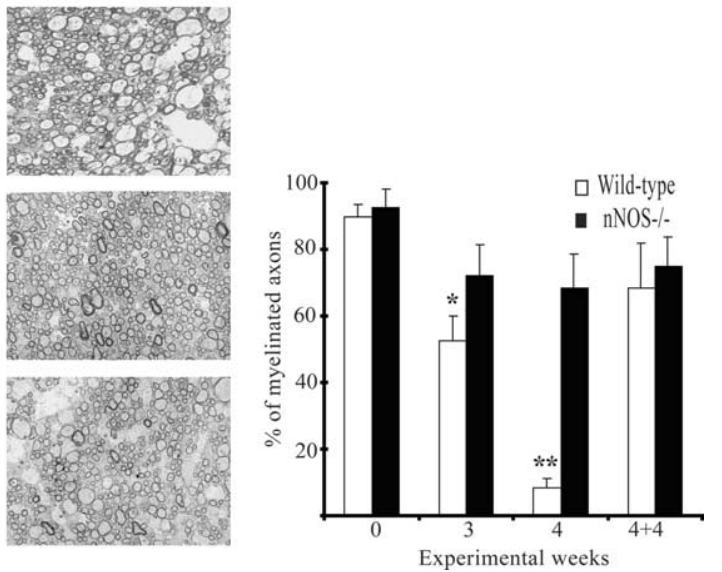

Figure 3. The minor loss of myelin exhibited by $n \mathrm{NOS}^{-1-}$ mice in response to cuprizone was further confirmed by electron microscopy. A, Electron micrographs show that, although the majority of axons of the corpus callosum in $n N \mathrm{NS}^{-1-}$ mice preserve their myelin, few myelinated axons were observed in wild-type mice after 4 weeks of exposure to the neurotoxic cuprizone. For the midline of the corpus callosum were photographed for each mouse as described in Materials and Methods. Scale bar, $1 \mu \mathrm{m}$. ${ }^{*} p<$ $0.05 ;{ }^{* *} p<0.01 . n=6-7$ mice for each time point derived from two different experiments.

Figure 4. Electron microscopy of cross sections of corpus callosum in wild-type and eNOS ${ }^{-/-}$mice. A large number of axons in the corpus callosum were counted from three different electron micrograph images of each mouse at different time points of cuprizone feeding. Scale bar, $1 \mu \mathrm{m} .{ }^{*} p<0.05 ;{ }^{* *} p<0.01 . n=6-7$ mice for each time point derived from two different

Oligodendrocyte precursors accumulate and differentiate in the demyelinating lesions in response to mature oligodendrocyte death (Matsushima and Morell, 2001). In view of the reduced oligodendrocyte death observed in $\mathrm{nNOS}^{-/-}$mice in response to cuprizone, we next investigated whether the absence of the constitutive isoforms of NOS influence the recruitment of oligodendroglial precursor during demyelination. As shown in Figure 7C, the number of NG2-positive cells was significantly higher in wildtype mice compared with $n N_{O S}{ }^{-/-}$mice during the whole experimental period. The reduced number of oligodendrocyte precursors detected in $n N^{-1-}$ mice correlates with their impairment in remyelination efficiency, suggesting that the survival of mature oligodendrocytes in $n \mathrm{NOS}^{-1-}$ mice may inhibit the repopulation of the demyelinating areas with nascent oligodendrocyte precursors. Figure $7 D$ shows no significant differences in the number of NG2-positive cells between wild-type and $\mathrm{eNOS}^{-/-}$mice in the corpus callosum in response to cuprizone. 
B

A WT
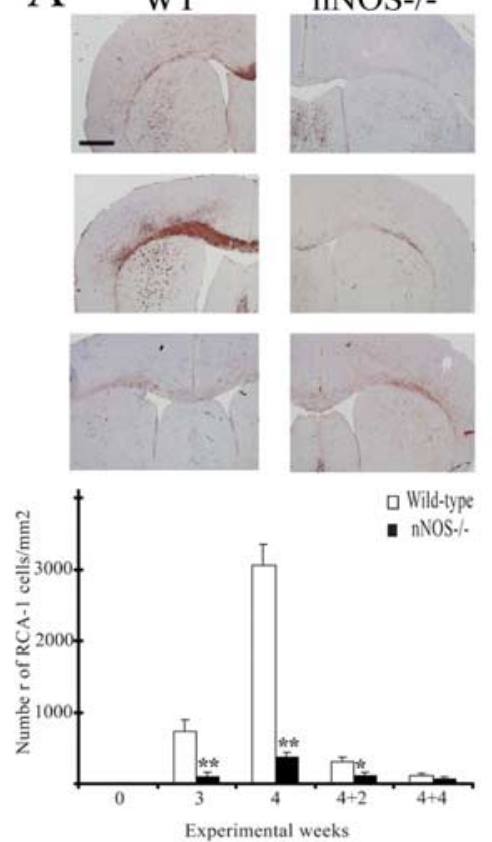

C
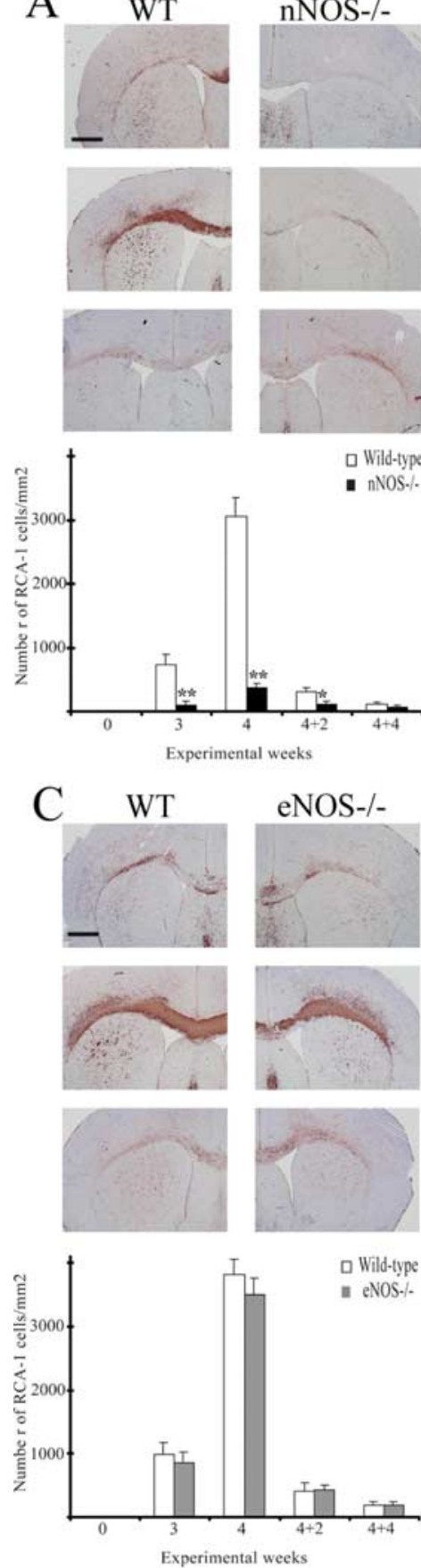

WT

3 weeks

4 weeks
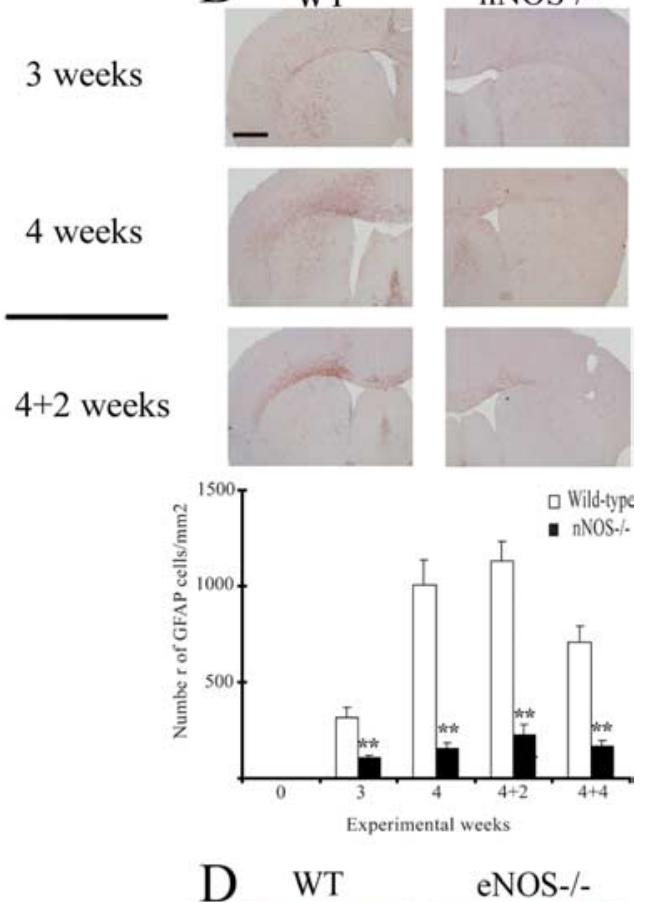

3 weeks

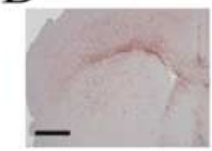

4 weeks
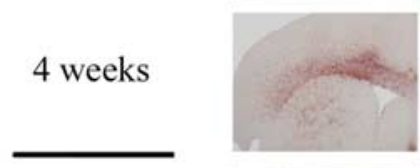

$4+2$ weeks
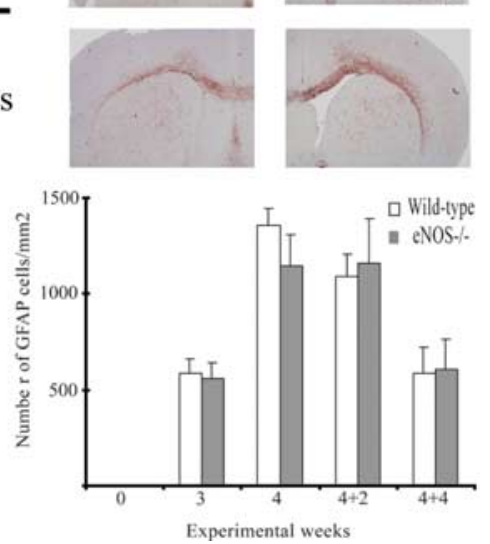

Figure 5. $n N \mathrm{NO}^{-1-}$ mice exhibit a dramatic decrease in the inflammatory cellular infiltrate in response to cuprizone feeding. Paraffin-embedded section from wild-type and $n \mathrm{NOS}^{-/-}$mice were stained with RCA-1 (A) and GFAP (B) antibodies. During cuprizone treatment, a massive accumulation of activated microglia/macrophages and astrocytes is observed inside and outside of the corpus callosum in wild-type mice. Cellular infiltrate is reduced after cuprizone removal in wild-type mice. Few RCA-1- and GFAP-positive cells are observed in the corpus callosum of $n \mathrm{NOS}^{-1-}$ mice during the whole experimental period. Representative coronal sections from wild-type and eNOS ${ }^{-1-}$ mice stained with RCA- $1(\boldsymbol{C})$ and GFAP $(\boldsymbol{D})$ antibodies are also shown. Cuprizone treatment leads to a massive accumulation of RCA-1-positive cells and severe astrogliosis in both wild-type and eNOS ${ }^{-1-}$ mice. RCA-1- and GFAP-positive cells were quantified by two independent observers in a blind manner, and the results are expressed as the mean of the number of positive cells in the corpus callosum at different time points of cuprizone feeding. Scale bar, $500 \mu \mathrm{m}$. ${ }^{*} p<0.05 ;{ }^{* *} p<0.01$.

\section{$n N O S^{-/-}$mice show a different pattern in the alteration of the expression of several genes in response to cuprizone feeding}

It has been documented that toxic demyelination is accompanied by an upregulation in the expression of several cytokines and growth
nNOS-/-
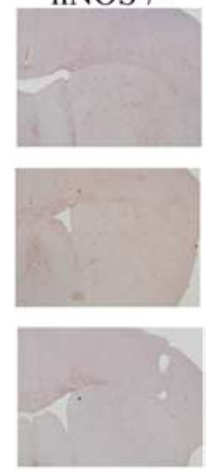

factors and by an extensive downregulation in the expression of several myelin proteins expressed by mature oligodendrocytes (Jurevics et al., 2002). In view of the observed differences in oligodendrocyte survival and recruitment of several cellular types in the corpus callosum between experimental groups in response to the toxic agent, we measured the expression of various molecules that have been implicated previously in demyelination/remyelination. After 3 weeks of cuprizone treatment, MOG expression was markedly downregulated in wild-type mice, which is in accordance with the greater rate of oligodendrocyte death seen in these mice (Fig. 8A). The expression of MOG was also downregulated in $n \mathrm{NOS}^{-/-}$mice, but $\mathrm{m} R N A$ levels for this myelin protein were significantly higher than in their wild-type controls during acute demyelination. When normal food was restored, MOG expression in wild-type mice was considerably increased, surpassing MOG expression levels of untreated mice. For $n N^{-1-}$ mice, MOG transcript levels remained under basal level after 2 weeks of feeding with normal food, corroborating the defective remyelination exhibited by these mice (Fig. 8A). During cuprizone treatment, no significant differences in MOG mRNA response were noted between wild-type and eNOS ${ }^{-/-}$ mice, although $e \mathrm{NOS}^{-\prime-}$ mice evidenced a delay in the recovery of MOG expression when normal food was restored (Fig. 8B). We next evaluated the gene expression of several cytokines and growth factors and found that the expression of the entire array of molecules analyzed (TNF $\alpha$, IGF-1, IL- $1 \beta$, and iNOS) was significantly higher in wildtype mice compared with $n \mathrm{NOS}^{-/-}$mice in response to cuprizone feeding (Fig. 8A). During demyelination and remyelination, no significant differences were observed in the expression of TNF $\alpha$, IL- $1 \beta$, and iNOS between wild-type and $e \mathrm{NOS}^{-/-}$mice. However, when IGF-1 expression levels were evaluated, it was observed that $e \mathrm{NOS}^{-/-}$ mice expressed significant lower levels of this grown factor after 4 weeks of cuprizone feeding compared with wild-type mice.

\section{Discussion}

NO is a labile molecule that has been associated with numerous pathologic processes. In particular, previous studies have suggested that NO plays a deleterious role in demyelinating diseases such as multiple sclerosis (Kolb and Kolb-Bachofen, 1998; Brenner et al., 2001; Duncan and Heales, 2005). In the CNS, oligodendrocytes, when compared with other glial cells, are extremely sensitive to damage by NO (Smith and Lassmann, 2002), and, in this respect, oligodendrocyte death may represent the underpinning mechanism in the pathophysiology of MS. 
NO produced by iNOS is locally secreted by inflammatory cells in response to CNS inflammatory stimuli. iNOS is capable of producing large quantities of NO when compared with the constitutive isoforms, nNOS and eNOS. For these reasons, most of the studies evaluating the effect of NO production in various forms of CNS pathology have been focused on NO produced by the former isoform. A recent report using the cuprizone model of demyelination explored the role of iNOS in demyelination and remyelination (Arnett et al., 2002). These investigators found that mice lacking iNOS showed a modest increase in the extent of demyelination in the corpus callosum.

Although constitutively expressed in the CNS, nNOS and eNOS are capable of being induced under some circumstances (Moncada and Higgs, 1995). In particular, treatment with certain neurotoxic agents increases expression of $\mathrm{mRNA}$ for nNOS in the hippocampus (Bagetta et al., 1993), and transection of the sciatic nerve in rats dramatically upregulates nNOS mRNA in the ipsilateral dorsal root ganglion (Verge et al., 1992). In the present study, we demonstrated upregulation of not only iNOS $\mathrm{m} R N A$ in the corpus callosum in response to cuprizone but also of nNOS mRNA. We also shown that mice lacking the gene for nNOS are almost completely protected against cuprizone-induced demyelination. Moreover, the lack of eNOS did not seem to contribute to the extent of demyelination; however, $\mathrm{eNOS}^{-/-}$mice exhibited a delay in their capacity to undergo regenerative remyelination when cuprizone was removed from the diet.

Our results showing that $n \mathrm{NOS}^{-/-}$ mice were highly protected against demyelination are in discordance with the suggested protective role of $\mathrm{NO}$ produced by iNOS in this model (Arnett et al., 2002). It is known that NO has pleiotropic physiological actions throughout the body (Moncada and Erusalimsky, 2002). Thus, it has been documented that NO exerts several actions on cell respiration, particularly that $\mathrm{NO}$ is able to inhibit complex IV in the respiratory chain on mitochondria (Brunori et al., 2004). As a result of this inhibition, NO has been reported to posses both pro-apoptotic and anti-apoptotic effects (Beltran et al., 2000; Xu et al., 2005). Because apoptosis appears to be the main mechanism leading to oligodendrocyte death in this model (Arnett et al., 2002), it is possible that differences in time, dose, and site of NO secretion by the different NOS isoforms in response to cuprizone may lead to divergent effects in oligodendrocyte apoptosis and, therefore, explain the differences between the various NOS mutant strains and wild-type mice.

Our results showed that the lack of nNOS expression notably modulates oligodendrocyte survival in response to cuprizone exposure because elevated number of mature oligodendrocytes were still observed in the corpus callosum after several weeks of
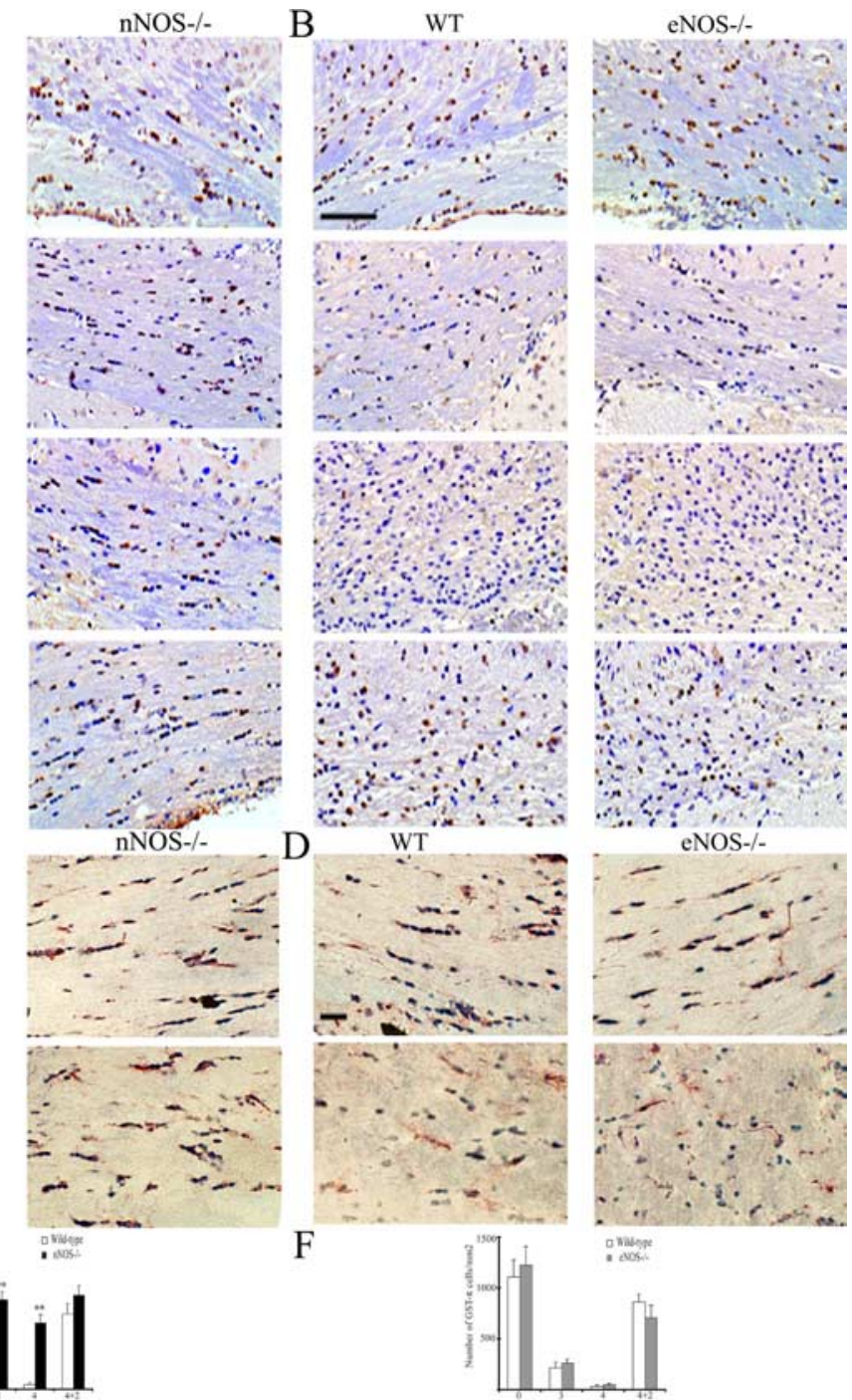

eNOS-/
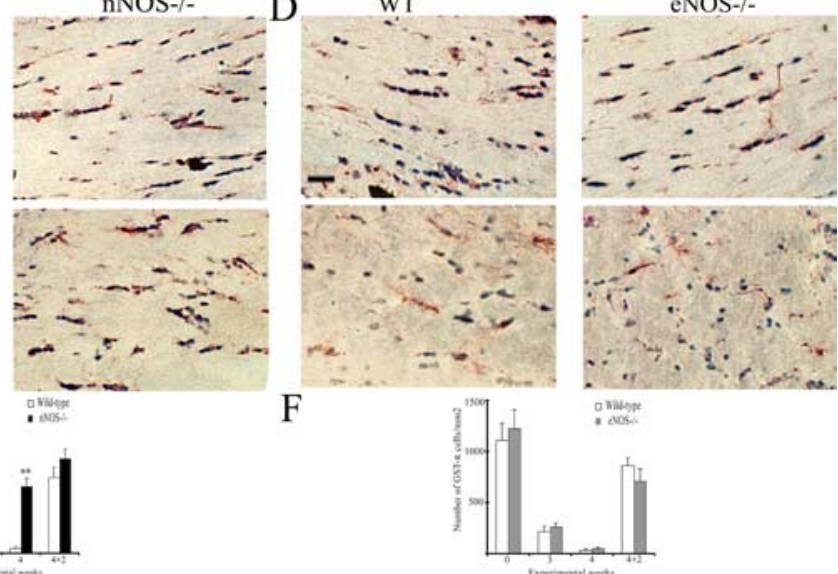

\section{西}

Figure 6. Mature oligodendrocytes are not depleted in $n \mathrm{NOS}^{-1-}$ mice in response to cuprizone feeding. Mature oligodendrotogether with their respective wild-type controls. The lack of the nNOS gene considerably protects mature oligodendrocytes

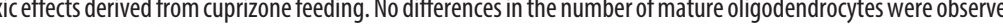
staining, $25 \mu \mathrm{m}$. GST- $\pi$-positive cells were also quantified, and results are expressed as mean of the number of GST- $\pi$-positive cells per square millimeter in the corpus callosum at different time points of cuprizone feeding $(\boldsymbol{E}, \boldsymbol{F}) .{ }^{*} p<0.05$; ${ }^{* *} p<0.01$.

cuprizone feeding in $n N^{-1-}$ mice. Accordingly, the numbers of cells undergoing apoptosis were greatly reduced in $n \mathrm{NOS}^{-/-}$ mice, suggesting that nNOS is a key component in the cascade of events after cuprizone administration.

The cuprizone model represents an excellent tool for studying the role of microglia/macrophages in demyelinating diseases. Our results showed that, after 3 and 4 weeks of cuprizone feeding, massive numbers of RCA-1-positive cells were present in the corpus callosum of wild-type mice. In sharp contrast, only few macrophages and/or activated microglia were observed in $n \mathrm{NOS}^{-1-}$ mice in response to cuprizone. These differences appear to be in accordance with the phagocytic role of microglia in the clearance of myelin debris after nerve injury (Minghetti and Levi, 1998). Because minor oligodendrocyte death was observed after cuprizone feeding in $n \mathrm{NOS}^{-/-}$mice, it is reasonable to assume that the number of phagocytic cells required for the clearance of myelin debris in those mice would be significantly lower than in wild-type mice. 


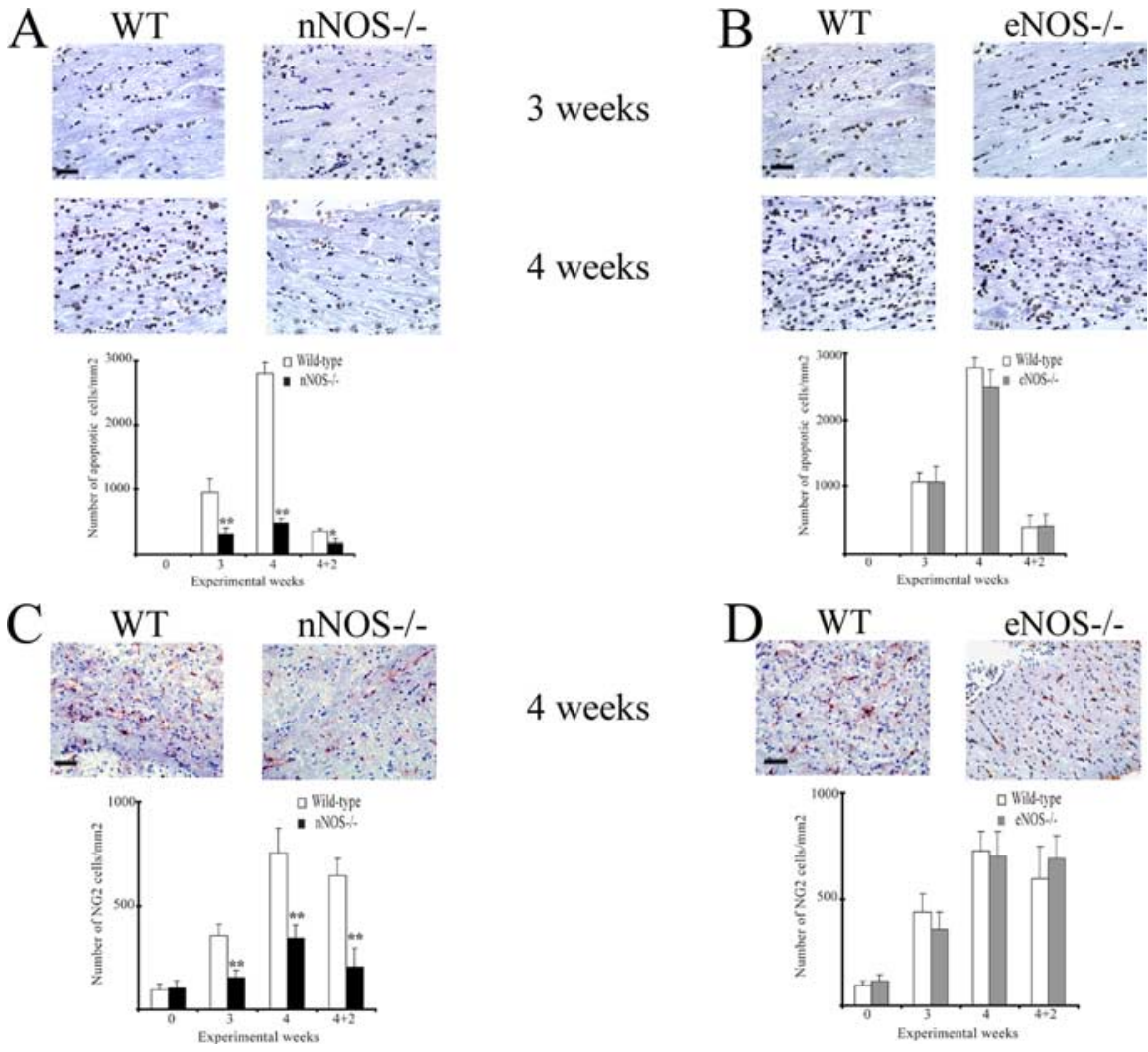

Figure 7. Representative coronal sections from nNOS $-1-$ mice $(\boldsymbol{A})$ and eNOS ${ }^{-1-}$ mice $(\boldsymbol{B})$ and their respective wild-type controls were stained for apoptosis using Apoptag Peroxidase in situ Apoptosis Detection kit as described in Materials and Methods. The number of cells undergoing apoptosis in the corpus callosum of $n N O S^{-1-}$ mice fed with cuprizone was significantly lower than that in wild-type mice. Scale bar, $25 \mu \mathrm{m}$. Effects of the lack of nNOS (C) and eNOS (D) genes on the accumulation of OPCs in response to cuprizone feeding. OPCs detected using NG2 antibody accumulate in the demyelinating corpus callosum in wild-type mice after 3 and 4 weeks of cuprizone treatment. Few NG2-positive cells were observed in the corpus callosum of $n \mathrm{NOS}^{-1-}$ mice in response to the neurotoxicant. NG2-positive cells were quantified as described in Materials and Methods. Scale bar, $25 \mu \mathrm{m} .{ }^{*} p<0.05 ;{ }^{* *} p<0.01$.

After CNS trauma, astrocytes rapidly proliferate at the site of the lesion and become activated, a process that is often referred as reactive astrogliosis or glial scar (Silver and Miller, 2004). It has been shown that, after several weeks of cuprizone feeding, massive astrogliosis takes place inside and outside the corpus callosum (Matsushima and Morell, 2001). Our results demonstrated that the reactive astrogliosis exhibited by $n \mathrm{NOS}^{-/-}$mice was greatly reduced compared with their wild-type littermates, which further supports the protective phenotype exhibited by $n \mathrm{NOS}^{-/-}$ mice in response to cuprizone. These observations are also in accordance with the significant reduction in the expression of several cytokines and grown factors mainly secreted by macrophages, activated microglia, and reactive astrocytes observed in $n \mathrm{NOS}^{-/-}$mice compared with wild-type mice.

The deleterious role of nNOS in CNS injury has been documented previously in other animal models of neurodegeneration. It has been shown that $n N O S^{-/-}$mice are protected against 1-methyl-4-phenyl-1,2,3,6-tetrahydropyridine-induced neurotoxicity, which is used as an animal model for Parkinson's disease (Przedborski et al., 1996). Although we still do not fully understand the reasons explaining the differences in susceptibility to acute demyelination exhibited by the different NOS isoforms mutant strains, the fact that the production of NO in mitochondria appears to be closely linked to the nNOS gene may explain the differences in apoptosis rate and subsequent demyelination observed in response to cuprizone feeding between various NOS isoforms mutant strains. In fact, several authors have suggested the existence of a new isoform of NOS known as mitochondrial isoform (mtNOS), which may produce NO locally at mitochondria and, therefore, modulate mitochondria respiration (Giulivi et al., 1998; Ghafourifar et al., 1999). In this regard, a recent study has documented that $n \mathrm{NOS}^{-/-}$mice show an impairment in the production of NO by mitochondria, suggesting that mtNOS may represent an alternative splice variant of nNOS (Kanai et al., 2001).

Interestingly, our results also revealed that $\mathrm{nNOS}$ mice remyelinate relatively slower compared with wild-type mice. Considering the minor damage exhibited by nNOS mice, one would expect a rapid regenerative remyelination once normal food was restored. Unexpectedly, demyelination was still apparent 2 weeks after cuprizone removal. Although activated microglia, macrophages, and reactive astrocytes can release several molecules that can aggravate the severity of the demyelinating lesion, they are also the predominant source of multitude of molecules with regenerative capabilities, which influence the recruitment and differentiation of OPCs (Diemel et al., 1998). Several studies have shown that OPCs, because of their ability to differentiate into myelinforming cells, are responsible for the subsequent remyelination after cuprizone feeding (Mason et al., 2001). In the current study, $n \mathrm{NOS}^{-/-}$mice did not respond with a consistent recruitment of inflammatory cells or reactive astrocytes in the demyelinating lesions, and, therefore, they did not upregulate the expression of several molecules such as IL- $1 \beta$, TNF- $\alpha$, and IGF- 1 to the same extent as the wild-type mice in response to cuprizone. In this regard, previous work using this model has pointed out to the importance of these latter molecules in promoting remyelination after CNS trauma (Arnett et al., 2001; Mason et al., 2001, 2003).

Here, we also revealed that $\mathrm{NOS}^{-1-}$ mice demyelinated to the same extent than wild-type mice, but they showed a slight delay in spontaneous remyelination when cuprizone was removed from the diet. Interestingly, although this impairment in remyelination was not correlated with a reduction in the number of OPCs in the lesioned areas, $\mathrm{eNOS}^{-/-}$mice upregulated IGF-1 mRNA levels to a lesser extent in response to cuprizone feeding. Several studies have pointed out to the important role that IGF-1 plays in the maturation of OPCs and therefore in the mechanisms leading to spontaneous remyelination after CNS trauma (Wilson et al., 2003).

Together, this study shows the important role that the constitutive isoforms of NOS plays in the demyelination and remyelination associated with the exposure to the neurotoxic cuprizone. In particular, the presence of the neuronal isoform significantly modulates the rate of oligodendrocyte death and the subsequent repopulation of the demyelinating areas with new myelinforming cells. Interestingly, the protection afforded by the lack of the neuronal isoform does not appear to be restricted to the cu- 


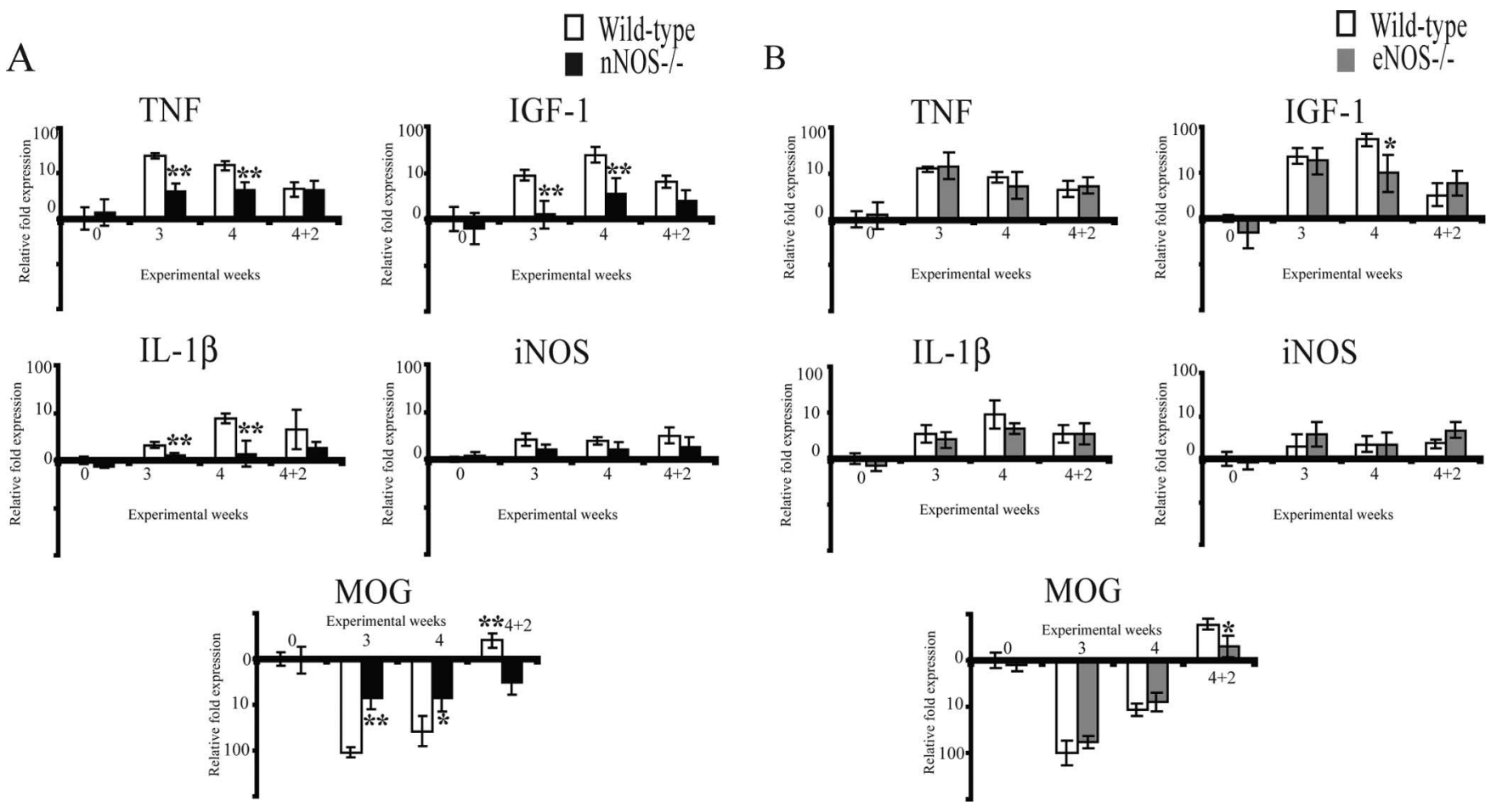

Figure 8. Relative gene expression of TNF- $\alpha$, IGF-1, IL-1 $\beta$, iNOS, and MOG during demyelination/remyelination induced by cuprizone in $n N O S^{-/-}$mice $(\boldsymbol{A})$ and eNOS ${ }^{-/-}$mice $(\boldsymbol{B})$ and their respective wild-type controls. Relative gene expression was measured by quantitative real-time $P C R$ using gene-specific primers and relative quantification using comparative $C t$ method was used for analyzing results. The results were expressed as relative fold change over the values for untreated mice. ${ }^{*} p<0.05 ;{ }^{* *} p<0.01$.

prizone model of demyelination because $n \mathrm{NOS}^{-/-}$mice develop a less severe symptomatology when experimental autoimmune encephalomyelitis was induced by myelin oligodendrocyte glycoprotein (D. O. Willenborg, unpublished results). Based on this, the data derived from our investigations should further stimulate the study of the role that the neuronal isoform of NOS plays in other animal models of demyelination, with the ultimate goal of developing future therapies for human demyelinating diseases as MS.

In conclusion, this study highlights the importance of considering the possible deleterious effect associated with the secretion of NO derived from other isoforms apart from iNOS in the treatment of demyelinating diseases.

\section{References}

Arnett HA, Mason J, Marino M, Suzuki K, Matsushima GK, Ting JP (2001) TNF alpha promotes proliferation of oligodendrocyte progenitors and remyelination. Nat Neurosci 4:1116-1122.

Arnett HA, Hellendall RP, Matsushima GK, Suzuki K, Laubach VE, Sherman P, Ting JP (2002) The protective role of nitric oxide in a neurotoxicantinduced demyelinating model. J Immunol 168:427-433.

Bagetta G, Corasaniti MT, Melino G, Paoletti AM, Finazzi-Agro A, Nistico G (1993) Lithium and tacrine increase the expression of nitric oxide synthase mRNA in the hippocampus of rat. Biochem Biophys Res Commun 197:1132-1139.

Beltran B, Mathur A, Duchen MR, Erusalimsky JD, Moncada S (2000) The effect of nitric oxide on cell respiration: a key to understanding its role in cell survival or death. Proc Natl Acad Sci USA 97:14602-14607.

Borgerding RA, Murphy S (1995) Expression of inducible nitric oxide synthase in cerebral endothelial cells is regulated by cytokine-activated astrocytes. J Neurochem 65:1342-1347.

Bredt DS, Snyder SH (1992) Nitric oxide, a novel neuronal messenger. Neuron 8:3-11.

Brenner T, Pinto F, Abramsky O, Gallily R (2001) Inhibition of nitric oxide production for down-regulation of CNS inflammation and demyelination. Prog Brain Res 132:499-506.
Brunori M, Giuffre A, Forte E, Mastronicola D, Barone MC, Sarti P (2004) Control of cytochrome c oxidase activity by nitric oxide. Biochim Biophys Acta 1655:365-371.

Diemel LT, Copelman CA, Cuzner ML (1998) Macrophages in CNS remyelination: friend or foe? Neurochem Res 23:341-347.

Duncan AJ, Heales SJ (2005) Nitric oxide and neurological disorders. Mol Aspects Med 26:67-96.

Franklin KBJ, Paxinos G (1997) The mouse brain in stereotaxic coordinates. San Diego: Academic.

Ghafourifar P, Schenk U, Klein SD, Richter C (1999) Mitochondrial nitricoxide synthase stimulation causes cytochrome $\mathrm{c}$ release from isolated mitochondria. Evidence for intramitochondrial peroxynitrite formation. J Biol Chem 274:31185-31188.

Giulivi C, Poderoso JJ, Boveris A (1998) Production of nitric oxide by mitochondria. J Biol Chem 273:11038-11043.

Hewett SJ, Corbett JA, McDaniel ML, Choi DW (1993) Interferon-gamma and interleukin- 1 beta induce nitric oxide formation from primary mouse astrocytes. Neurosci Lett 164:229-232.

Huang Z, Huang PL, Panahian N, Dalkara T, Fishman MC, Moskowitz MA (1994) Effects of cerebral ischemia in mice deficient in neuronal nitric oxide synthase. Science 265:1883-1885.

Huang Z, Huang PL, Ma J, Meng W, Ayata C, Fishman MC, Moskowitz MA (1996) Enlarged infarcts in endothelial nitric oxide synthase knockout mice are attenuated by nitro-L-arginine. J Cereb Blood Flow Metab 16:981-987.

Jurevics H, Largent C, Hostettler J, Sammond DW, Matsushima GK, Kleindienst A, Toews AD, Morell P (2002) Alterations in metabolism and gene expression in brain regions during cuprizone-induced demyelination and remyelination. J Neurochem 82:126-136.

Kanai AJ, Pearce LL, Clemens PR, Birder LA, VanBibber MM, Choi SY, de Groat WC, Peterson J (2001) Identification of a neuronal nitric oxide synthase in isolated cardiac mitochondria using electrochemical detection. Proc Natl Acad Sci USA 98:14126-14131.

Kolb H, Kolb-Bachofen V (1998) Nitric oxide in autoimmune disease: cytotoxic or regulatory mediator? Immunol Today 19:556-561.

Linnington C, Webb M, Woodhams PL (1984) A novel myelin-associated glycoprotein defined by a mouse monoclonal antibody. J Neuroimmunol 6:387-396. 
Livak KJ, Schmittgen TD (2001) Analysis of relative gene expression data using real-time quantitative PCR and the 2(-Delta Delta C $(\mathrm{T})$ ) method. Methods 25:402-408.

Ma L, Morita I, Murota S (1994) Presence of constitutive type nitric oxide synthase in cultured astrocytes isolated from rat cerebra. Neurosci Lett 174:123-126.

Mason JL, Jones JJ, Taniike M, Morell P, Suzuki K, Matsushima GK (2000) Mature oligodendrocyte apoptosis precedes IGF-1 production and oligodendrocyte progenitor accumulation and differentiation during demyelination/remyelination. J Neurosci Res 61:251-262.

Mason JL, Suzuki K, Chaplin DD, Matsushima GK (2001) Interleukin-1 $\beta$ promotes repair of the CNS. J Neurosci 21:7046-7052.

Mason JL, Xuan S, Dragatsis I, Efstratiadis A, Goldman JE (2003) Insulinlike growth factor (IGF) signaling through type 1 IGF receptor plays an important role in remyelination. J Neurosci 23:7710-7718.

Matsushima GK, Morell P (2001) The neurotoxicant, cuprizone, as a model to study demyelination and remyelination in the central nervous system. Brain Pathol 11:107-116.

McMahon EJ, Suzuki K, Matsushima GK (2002) Peripheral macrophage recruitment in cuprizone-induced CNS demyelination despite an intact blood-brain barrier. J Neuroimmunol 130:32-45.

Merrill JE, Murphy SP, Mitrovic B, Mackenzie-Graham A, Dopp JC, Ding M, Griscavage J, Ignarro LJ, Lowenstein CJ (1997) Inducible nitric oxide synthase and nitric oxide production by oligodendrocytes. J Neurosci Res 48:372-384.

Minghetti L, Levi G (1998) Microglia as effector cells in brain damage and repair: focus on prostanoids and nitric oxide. Prog Neurobiol 54:99-125.

Moncada S, Erusalimsky JD (2002) Does nitric oxide modulate mitochondrial energy generation and apoptosis? Nat Rev Mol Cell Biol 3:214-220.

Moncada S, Higgs EA (1995) Molecular mechanisms and therapeutic strategies related to nitric oxide. FASEB J 9:1319-1330.

Moro MA, Cardenas A, Hurtado O, Leza JC, Lizasoain I (2004) Role of nitric oxide after brain ischaemia. Cell Calcium 36:265-275.

Murphy S, Simmons ML, Agullo L, Garcia A, Feinstein DL, Galea E, Reis DJ, Minc-Golomb D, Schwartz JP (1993) Synthesis of nitric oxide in CNS glial cells. Trends Neurosci 16:323-328.

Nathan C, Xie QW (1994) Nitric oxide synthases: roles, tolls, and controls. Cell 78:915-918.

Plant SR, Arnett HA, Ting JP (2005) Astroglial-derived lymphotoxin-alpha exacerbates inflammation and demyelination, but not remyelination. Glia 49:1-14.
Popko B, Corbin JG, Baerwald KD, Dupree J, Garcia AM (1997) The effects of interferon-gamma on the central nervous system. Mol Neurobiol 14:19-35

Przedborski S, Jackson-Lewis V, Yokoyama R, Shibata T, Dawson VL, Dawson TM (1996) Role of neuronal nitric oxide in 1-methyl-4-phenyl1,2,3,6-tetrahydropyridine (MPTP)-induced dopaminergic neurotoxicity. Proc Natl Acad Sci USA 93:4565-4571.

Quarles RH (1997) Glycoproteins of myelin sheaths. J Mol Neurosci 8:1-12.

Shi SR, Cote RJ, Liu C, Yu MC, Castelao JE, Ross RK, Taylor CR (2002) A modified reduced-temperature antigen retrieval protocol effective for use with a polyclonal antibody to cyclooxygenase-2 (PG 27). Appl Immunohistochem Mol Morphol 10:368-373.

Silver J, Miller JH (2004) Regeneration beyond the glial scar. Nat Rev Neurosci 5:146-156.

Simmons ML, Murphy S (1992) Induction of nitric oxide synthase in glial cells. J Neurochem 59:897-905.

Smith KJ, Lassmann H (2002) The role of nitric oxide in multiple sclerosis. Lancet Neurol 1:232-241.

Solly SK, Thomas JL, Monge M, Demerens C, Lubetzki C, Gardinier MV, Matthieu JM, Zalc B (1996) Myelin/oligodendrocyte glycoprotein (MOG) expression is associated with myelin deposition. Glia 18:39-48.

Suzuki K, Kikkawa Y (1969) Status spongiosus of CNS and hepatic changes induced by cuprizone (biscyclohexanone oxalyldihydrazone). Am J Pathol 54:307-325.

Verge VM, Xu Z, Xu XJ, Wiesenfeld-Hallin Z, Hokfelt T (1992) Marked increase in nitric oxide synthase mRNA in rat dorsal root ganglia after peripheral axotomy: in situ hybridization and functional studies. Proc Natl Acad Sci USA 89:11617-11621.

Wilson HC, Onischke C, Raine CS (2003) Human oligodendrocyte precursor cells in vitro: phenotypic analysis and differential response to growth factors. Glia 44:153-165.

Wu J, Lin Q, Lu Y, Willis WD, Westlund KN (1998) Changes in nitric oxide synthase isoforms in the spinal cord of rat following induction of chronic arthritis. Exp Brain Res 118:457-465.

Wu J, Fang L, Lin Q, Willis WD (2001) Nitric oxide synthase in spinal cord central sensitization following intradermal injection of capsaicin. Pain 94:47-58.

Xu W, Charles IG, Moncada S (2005) Nitric oxide: orchestrating hypoxia regulation through mitochondrial respiration and the endoplasmic reticulum stress response. Cell Res 15:63-65. 